\title{
A COMPARATIVE ANALYSIS OF CYCLIC FATIGUE OF A NEW PREHEATED MACHINED CM WIRE ENDODONTIC FILES AFTER EXPOSURE TO DIFFERENT IRRIGANTS
}

\author{
Hala Fayek Khalil* and Sara Samir El Mallah **
}

\begin{abstract}
AIM: Analysis of cyclic fatigue of a new preheated machined CM wire MPro endodontic files after exposure to lycopene, curcumin and Soduim hypochlorite for two different immersion observation periods; 5 minutes and 10 minutes

Methodology: Eighteen size 20 MPro files were used in this study, divided into three groups of 6 files each according to irrigant used: Group I lycopene, Group II curcumin and Group III Soduim hypochlorite. All files were immersed in irrigants for either 5 or 10 minutes. The cyclic fatigue tess were performed on all files of both immersion periods using a static cyclic fatigue testing device, which have an artificial stainless steel canal and tested using a custom-made static cyclic fatigue testing apparatus. Parameters recorded were time to fracture, number of cycles to failure (NCF) and mean length of fractured segments.
\end{abstract}

Results: Results showed no statistically significant difference between the different irrigants at the two observation periods and within the same group regarding time to fracture, number of cycles to failure (NCF) and mean length of fractured segments.

Conclusion: All tested irrigants lycopene, curcumin and Soduim hypochlorite had same effect on cyclic fatigue of the preheated machined CM wire Mpro endodontic files when used for 5 or 10 minutes.

\section{INTRODUCTION}

Nickel-Nickel-titanium instruments are popular in endodontics compared to stainless steel instruments.(1) The instrument related procedural errors led to emergence of a new nitinol rotary instrument files with controlled memory, made from a wire (termed CM-wire), these files keeps the shape of the canal even when it is out of it. ${ }^{(2,3)} \mathrm{CM}$ Wire (DS Dental, Johnson City, TN) was announced in 2010, contrived by a thermos-mechanical procedure to increase flexibility, decrease shape memory, increase transformation temperatures (Af to about $50^{\circ} \mathrm{C}$ ) which allows instruments to be pre-curved prior to

* Lecturer of Endodontics Faculty of Dentistry The British University in Egypt,

** Lecturer of Endodontics Faculty of Dentistry Fayoum University 
use. Sterilization will get the file back to original shape. The Af of CM files is above body temperature. File at body temperature will show martensitic R-phase and austenitic structure. ${ }^{(4)}$

Cyclic fatigue fracture, the leading cause of instrument fracture occurs when the file rotates in a curved root canal in repetitive cycles of extension and compression in region of highest bending stress ${ }^{(5,6)}$. Gambarini et al.2008 ${ }^{(7)}$, Praisarnti et al. ${ }^{(8)}$ and Zender ${ }^{(9)}$ stated that fatigue resistance is of NiTi rotary is affected by material properties, cross-sectional design, metal surface treatments, metallurgical characterization and root canal irrigants.

Chemomechanical preparation cause reduction in the bacterial populations located in the main root canal. ${ }^{(10)}$ The choice of an irrigant depends on its effectiveness as lubricants , flush debris, smear layer removal and acting on virulent bacteria present in the canal. Irrigants with different chemical composition of have different effect on pulp, necrotic tissues and microorganisms. ${ }^{(11)}$ Because of its anitimicrobial and organic tissue dissolving ability, Sodium hypochlorite $(\mathrm{NaOCl})$ became the most used irrigant but it is toxic to the periapical tissues and weakens dentine by reducing its flexural strength and resilience making it susceptible to deformation and fractures. ${ }^{(12)}$

Studies by Arumugam et al ${ }^{[13]}$ Abraham et al

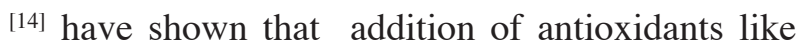
lycopene (LP), grape seed extract on bleached enamel have increased bond strength of enamel to composite resin restorations.

Now, there is a growing interest in natural remedies to be part of dental treatment ${ }^{(15)}$. Turmeric (Curcuma longa) is used as seasoning and food stabilizer in China, South east Asia and India, used in inherent medicine for the treatment of several diseases. Curcumin (diferuloylmethane), the main active ingredient of turmeric showed biological actions as antioxidant, anti-inflammatory and antimicrobial activities ${ }^{[16-18]}$. Many studies have stated a wide spectrum of activities to material ${ }^{[19,20]}$ which provides a suitable basis for thinking of its endodontic applications. Turmeric's antimicrobial action is due to its destruction of the assembly of a protein-filamenting temperature-sensitive mutant Z (FTSZ) profilaments and enhances the GTPase activity of FTSZ which are detrimental to bacteria ${ }^{(21)}$

The aim of our study is to analyze cyclic fatigue of a new preheated machined CM wire M Pro endodontic files under a static model After immersion in lycopene $5 \%$, Curcumin or sodium hypochlorite $5.25 \%$ for two observation periods 5 or 10 minutes.

\section{METHODS}

Eighteen size 20 MPro files (Foshan stardent equipment co limited, Gungdon, China) were used in this study, divided into three groups of 6 files each according to irrigant: Group I lycopene 5\% water solution (puritan's pride, Hulbrook ,NY, USA) Group II curcumin water solution (puritan's pride, ronkonkoma ,NY, USA) Group III Sodium hypochlorite $5.25 \%$. All irrigants were prepared according to literature searched and used at room temperature. Each group was subdivided according to immersion period : 5 minutes and 10 minutes. Before the static fatigue test, each file was examined for defects with a stereomicroscope (Leica MZ 12.5, Heerbrugg, Germany) under x10 magnification.

All files were cleaned after immersion in ultrasonic cleaner to remove traces of irrigants after immersion for the two observation periods. Fatigue tests were performed using a static cyclic fatigue testing device, composed of two parts First section; consisted of the stainless steel block part, which has an artificial canal with an inner diameter of 1.5 $\mathrm{mm}$, a $60^{\circ}$ angle of curvature and a curvature radius of $5 \mathrm{~mm}$ and has a Plexiglas preventive cover. The latter section; included an Instron universal testing machine (Massachusetts, USA) machine with a hand 
piece holder part that positioned the hand piece in a precise relationship to the stainless steel block when testing file inside the artificial canal. The two main parts of the apparatus were attached the steel base .

The file to be tested was inserted in the artificial canal to Working length of $16 \mathrm{~mm}$. The endo motor (Saeshin E cube, Saeshin precision Co., LTD. south korea) was set at a Continuous rotational speed 450 rpm and Torque of 2 newton. All files were rotated until fracture occurred .

Parameters recorded were time to fracture, number of cycles to failure and mean length of unfractured segments measured with a digital micro caliper and recorded.

\section{RESULTS}

Statistical analysis was performed using IBM SPSS Statistics Version 2.0 for Windows. Data was presented as mean and standard deviation (SD). The significance level was set at $\mathrm{P} \leq 0.05$. KolmogorovSmirnov and Shapiro-Wilk tests were used to assess data normality. Because of the small sample size, a non-parametric test was used. Kruskal-Wallis test followed by Mann-Whitney U test was performed to compare between the different irrigants at each immersion time. Mann-Whitney $U$ test was conducted to compare between the two immersion times within each irrigant group.

\section{Time to fracture and Number of cycles to} failure (NCF): There was no statistically significant difference between the different irrigants either at 5 mins or 10 mins immersion time or within each irrigant group. (Table $1 \& 2$ )

TABLE (1): Mean \pm SD and P-value for the effect of irrigant type and immersion time on time to fracture (min.) of MPro files.

\begin{tabular}{|c|c|c|c|}
\hline \multirow{2}{*}{ Irrigant type } & \multicolumn{2}{|c|}{ Immersion time } & \multirow{2}{*}{ P-value } \\
\cline { 2 - 3 } & $\mathbf{5}$ mins & $\mathbf{1 0 ~} \mathbf{~ m i n s}$ & \\
\hline Lycopene & $6.48 \pm 2.51$ & $12.13 \pm 7.31$ & 0.275 \\
\hline Curcumin & $4.80 \pm 0.72$ & $6.46 \pm 1.24$ & 0.077 \\
\hline NaOCl & $8.23 \pm 0.85$ & $11.81 \pm 1.24$ & 0.050 \\
\hline P-value & 0.148 & 0.099 & \\
\hline
\end{tabular}

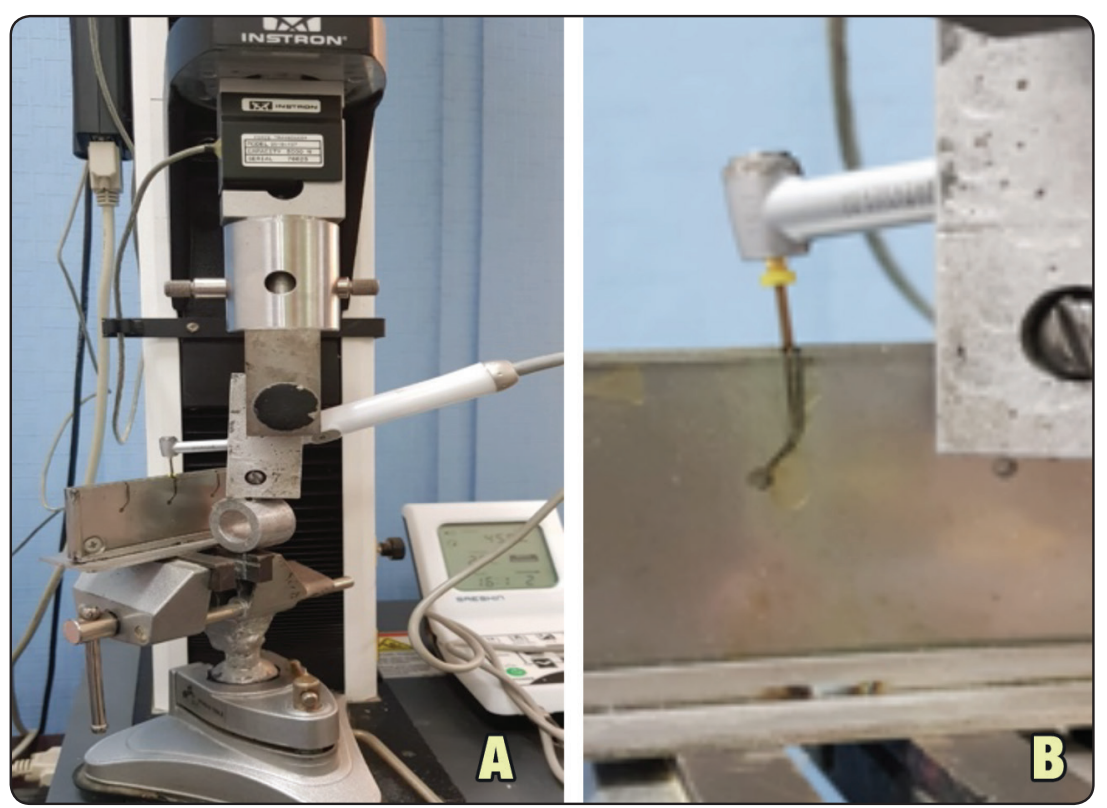

Fig. (1) Showing: (a) the cyclic fatigue device composed of two parts First section; stainless steel block part, with an artificial canal with an inner diameter of $1.5 \mathrm{~mm}$, a $60^{\circ}$ angle of curvature and a curvature radius of $5 \mathrm{~mm}$ and has a Plexiglas preventive cover that prevent fractured part of the file from slipping out. Second section; included an Instron universal testing machine (Massachusetts, USA )machine with a hand piece holder part that positioned the hand piece in a precise relationship to the stainless steel block when testing file inside the artificial canal. The two main parts of the apparatus were attached the steel base (b) the file inserted $16 \mathrm{~mm}$ deep in the simulated canal in the metal block. 
TABLE (2): Mean \pm SD and P-value for the effect of irrigant type and immersion time on number of cycles to failure (NCF) of MPro files.

\begin{tabular}{|c|c|c|c|}
\hline \multirow{2}{*}{$\begin{array}{c}\text { Irrigant } \\
\text { type }\end{array}$} & \multicolumn{2}{|c|}{ Immersion time } & \multirow{2}{*}{ P-value } \\
\cline { 2 - 4 } & $\mathbf{5}$ mins & $\mathbf{1 0}$ mins & \\
\hline Lycopene & $2920 \pm 1132.50$ & $5460 \pm 3291.57$ & 0.275 \\
\hline Curcumin & $2160 \pm 324.50$ & $2910 \pm 559.84$ & 0.077 \\
\hline NaOCl & $3703.5 \pm 382.81$ & $5314.5 \pm 558$ & 0.050 \\
\hline P-value & 0.148 & 0.099 & \\
\hline
\end{tabular}

$P \leq 0.05$

Un Fractured part length_showed no statistically significant difference between the different irrigants either at 5 mins or 10 mins immersion time or Within each irrigant group. (Table.3)

TABLE (3): Mean \pm SD and P-value for the effect of irrigant type and immersion time on unfractured segment length $(\mathrm{mm})$ of MPro files.

\begin{tabular}{|c|c|c|c|}
\hline \multirow{2}{*}{$\begin{array}{c}\text { Irrigant } \\
\text { type }\end{array}$} & \multicolumn{2}{|c|}{ Immersion time } & \multirow{2}{*}{ P-value } \\
\cline { 2 - 3 } & $\mathbf{5}$ mins & $\mathbf{1 0}$ mins & \\
\hline Lycopene & $19.70 \pm 1.21$ & $19.70 \pm 1.57$ & 0.827 \\
\hline Curcumin & $21.6 \pm 1.00$ & $22.15 \pm 1.80$ & 0.827 \\
\hline NaOCl & $20.63 \pm 0.33$ & $21.50 \pm 0.87$ & 0.050 \\
\hline P-value & 0.113 & 0.288 & \\
\hline
\end{tabular}

$P \leq 0.05$

\section{DISCUSSION}

For successful root canal treatment, the removal of pulpal tissue, microorganisms, and their products is important. ${ }^{(22,23)}$ In studies of the cyclic fatigue endurance of NiTi files, it is difficult to eliminate all factors that can affect the results. ${ }^{(24)}$ Although using extracted human teeth in cyclic fatigue studies simulates clinical conditions, it is not possible to standardize the anatomical variations of teeth. ${ }^{(25)}$ In our study, standard stainless steel artificial canals were employed to minimize various factors that can influence the study results.

Capar et al ${ }^{(26)}$ reported that HyFlex CM file had the highest resistance to cyclic fatigue. Authors attributed that to the thermomechanical processes applied during its production and emphasized that other CM files could also show high cyclic fatigue resistance. Both Hyflex and the Mpro file share same thermomechanical processes applied during production. The cutting parts of the instruments were immersed in lycopene $5 \%$, curcumin and $5.25 \% \mathrm{NaOCl}$ at $37^{\circ} \mathrm{C}$ for 5 or $10 \mathrm{~min}$.

Factors influencing the fatigue resistance include file design, cross-sectional geometry and diameters of core, tip size, taper of the tested file, radii, degree of curvature, rotation speed, torque, and movement kinematics. ${ }^{(27-29)}$. In the present study, we used one type of file and same size in standardized artificial canals $\left(60^{\circ}\right.$ angle of curvature and a curvature radius of $3 \mathrm{~mm}$ ) and same rotation speed $(450 \mathrm{rpm})$, rotation type (continuous) were set to leave only two variables the type of irrigant and the time of immersion of the file in it.

Sodium hypochlorite $(\mathrm{NaOCl})$ is an effective antimicrobial that dissolve tissue ${ }^{(30,31)}$ The use of $\mathrm{NaOCl}$ to irrigate root canals is the gold standard to achieve tissue dissolution and disinfection (8) Thus, NiTi instruments come in contact with this solution during the chemomechanical preparations or cleaning procedures. ${ }^{(32)}$

Our results recorded no statistical significant difference between materials among the two observation periods and also showed no statistical significant difference between the materials within same observation period. In the time to fracture the highest time mean was $\mathrm{NaOCl}$ with $8.23 \pm 0.85$ and the lowest time mean was curcumin with $4.80 \pm$ 0.72 at 5 minutes. The highest mean was lycopene with12.13 \pm 7.31 and lowest mean was curcumin with $6.46 \pm 1.24$ at 10 minutes. These numbers are higher than the numbers recorded by Karataşlıoğlu, et al. ${ }^{(33)}$ 
In the part recording the Number of cycles to failure $(\mathrm{NCF})$ : the highest number of cycles to fracture mean was $\mathrm{NaOCl}$ with3703.5 \pm 382.81 and Lowest number was curcumin with $2160 \pm$ 324.50 at $5 \mathrm{~min}$. Highest number was lycopene $5460 \pm 3291.57$ and the Lowest number to fracture was curcumin $2910 \pm 559.84$ at 10 minutes. These numbers are in average with the numbers recorded by Yilmaz and Ozyürek ${ }^{(34)}$. Our results were much higher than the numbers recorded by Cai et al., ${ }^{(6)}$ where they tested new and immersed hyflex files for 10 minutes in $\mathrm{NaOCl} 5.25 \%$ and less than Shen etal., ${ }^{(35)}$ where they tested typhoon CM files after immersion in $6 \% \mathrm{NaOCl}$ for 25 minutes. The difference in numbers which is not high may be attributed to the difference in file design between the typhoon and the Mpro.

These results prove that the immersion in lycopene ,Curcumin and $\mathrm{NaOCl}$ did not significantly decrease the cyclic fatigue resistance of $\mathrm{CM}$ wire files and that the cyclic fatigue resistance of CM files is 300 to $800 \%$ more than the conventional files as stated by Shen et al ${ }^{(36)}$ and using sodium hypochlorite for short term irrigant did not decrease the cyclic fatigue resistance of the files. Pedulla et al $201{ }^{(37)}$ stated that If corrosion affects the instrument in different area than the maximuim stress, the resistance to cyclic fatigue of the instrument will not be affected.

In the UnFractured part length:Longest part remaining record at $5 \mathrm{~min}$ is curcumin (file broke more apically) $21.6 \pm 1.00$ And the Shortest part remaining was lycopene $19.70 \pm 1.21$. Longest part remaining recorded at $5 \mathrm{~min}$ is curcumin (file broke more apically) $19.70 \pm 1.57$. Shortest part remaining was lycopene $19.70 \pm 1.21$. these results came in accordance with the results of Karataşlıoğlu, el., ${ }^{(33)}$.

According to our study although the results were insignificantly different between irrigants and between immersion times, lycopene as an irrigant recorded the best results. Lycopene is a natural antioxidant which is a substance that delay or inhibit oxidation of oxidizable substrate at lower concentration. Its addition increase the bond strength of enamel to composite resin restoration ${ }^{(38)}$. Antioxidants as irrigants will cause better dentinal tubule penetration of sealers and will not affect the file performance or cyclic fatigue.

Curcumin 5 minutes immersion time recorded the lowest data in both the time to fracture and the number of cycles to failure and recorded the longest unfractured part (file broke more apically). The corrosive potential of curcumin affected the file more apically where file core is thinner reducing its fatigue resistance and early file failure.

\section{CONCLUSION}

All tested irrigants lycopene, curcumin and Soduim hypochlorite had same effect on cyclic fatigue of the preheated machined CM wire Mpro endodontic files when used for 5 or 10minutes .

\section{REFERENCES}

1 Yahata Y, Yoneyama T, Hayashi Y, Ebihara A, Doi H, Hanawa T, Suda H. Effect of heat treatment on transformation temperatures and bending properties of nickel titanium endodontic instruments. Int Endod J 2009;42:621-6.

2- Ninan E, Berzins DW. Torsion and bending properties of shape memory and superelastic nickel-titanium rotary instruments. J Endod 2013; 39(1): 101-104.

3- Singh H and Kapoor P Hyflex CM and EDM Files: Revolutionizing the Art and Science of Endodontics. J Dent Health Oral Disord Ther 2016; 5(7): 00182.

4- Srivastava S, Alghadouni MA, Alotheem HS Current Strategies in Metallurgical Advances of Rotary NiTi Instruments: A Review . J Dent Health Oral Disord Ther 2018; 9(1): 00333.

5- Gambarini G, Gergi R, Naaman A, Osta N, Al Sudani D. Cyclic fatigue analysis of twisted file rotary NiTi instruments used in reciprocating motion. Int Endod J 2012; 45, 802-6.

6- Cai JJ, Tang XN \& Ge JY. Effect of irrigation on surface roughness and fatigue resistance of controlled memory wire nickel-titanium instruments. Int Endod J 2017; 50: 718-724. 
7- Gambarini G, Grande NM, Plotino G et al. Fatigue resistance of engine-driven rotary nickel-titanium instruments produced by new manufacturing methods. J Endod 2008;34, 1003-5.

8- Praisarnti C, Chang JW, Cheung GS (2010) Electropolishing enhances the resistance of nickel-titanium rotary files to corrosion-fatigue failure in hypochlorite. J Endod 36, 1354-7.

9- Zehnder M. Root canal irrigants. J Endod 2006; 32: 389-98.

10- Brito PR, Machado de Oliveria JC, Alves FR, De-Deus $\mathrm{G}$, Lopes HP et al.Comparison of the effectiveness of three irrigation techniques in reducing intracanal Enterococcus faecalis populations: an in vitro study. J Endod. 2009;35:1422-7.

11- Wali IE, Eid GEM, Omar WA and ElRafie S. The Antimicrobial Efficacy of Ozonated Water, Chlorhexidine and Sodium Hypochlorite against Single Species Biofilms of Enterococcus faecalis and Candida albicans. Egyptian Journal of Medical Microbiology. 2008; 17:419-427.

12- Murray PE, Farber RM, Namerow KN, Kuttler S and Garcia-Godoy F. Evaluation of Morinda citrifolia as an Endodontic Irrigant. J Endod. 2008;34:66 -70.

13- Arumugam MT, Nesamani R, Kittappa K, Sanjeev K, Sekar M. Effect of various antioxidants on the shear bond strength of composite resin to bleached enamel: An in vitro study. J Conserv Dent 2014;17:22-6.

14- Abraham S, Ghonmode WN, Saujanya KP, Jaju N, Tambe $\mathrm{VH}$, Yawalikar PP. Effect of grape seed extracts on bond strength of bleached enamel using fifth and seventh generation bonding agents. J Int Oral Health 2013;5:101-7

15- Little JW. Complementary and alternative medicine: impact on dentistry. Oral Surg Oral Med Oral Pathol Oral Radiol Endod 2004;98:137-45.

16- Banerjee A, Nigam SS. Antimicrobial efficacy of the essential oil of Curcuma longa. Indian J Med Res 1978;68: 864-6.

17- Goel A, Boland CR, Chauhan DP. Specific inhibition of cyclooxygenase-2 [COX-2] expression by dietary curcumin inHT-29 human colon cancer cells. Cancer Lett 2001;172:111-18.

18- Srihari Rao T, Basu N, Siddqui HH. Anti-inflammatory activity of curcumin analogues. Indian J Med Res 1982;75: 574-8.
19- Kumar V, Lewis SA, Mutalik S, Shenoy DB, Venkatesh, Udupa N, et al. Biodegradable microspheres of curcumin for treatment of inflammation. Indian J Physiol Pharmacol 2002;46:209-17.

20- Satoskar RR, Shah SJ, Shenoy SG. Evaluation of anti-inflammatory property of curcumin [diferuloyl methane] in patients with postoperative inflammation. Int J Clin Pharmacol Ther Toxicol 1986;24:651-4.

21- Rai D, Singh JK, Roy N, Panda D. Curcumin inhibits FTSZ assembly: An attractive mechanism for its antibacterial activity. Biochem J 2008 ; 410:147-55.

22- Basmadjian-Charles C, Farge P, Bourgeois D, Lebrun T. Factors influencing the long-term results of end- odontic treatment: a review of the literature. Int Dent J 2002; 52:81-6.

23- Siqueira JF, Rôças IN. Clinical implications and microbiology of bacterial persistence after treatment procedures. J Endod 2008;34:1291-301.

24- Pereira ES, Gomes RO, Leroy AM, Singh R, Peters OA, Bahia MG, et al. Mechanical behavior of M-Wire and conventional NiTi wire used to manufacture rotary endodontic instruments. Dent Mater 2013;29:318-24.

25- Berendt C, Yang J. Endodontic instruments with improved fatigue resistance. In: International Conference on Shape Memory and Superelastic Technologies; 2006: ASM International Pacific Grove, CA.

26- Capar ID, Ertas H, Arslan H. Comparison of cyclic fatigue resistance of novel nickel-titanium rotary instruments. Aust Endod J 2015;41:24-8.

27- Zhang E-W, Cheung GS, Zheng Y-F. Influence of crosssectional design and dimension on mechanical behavior of nickel-titanium instruments under torsion and bending: A numerical analysis. J Endod 2010;36:1394-98.

28- Martin B, Zelada G, Varela P, Bahillo J, Magán F, Ahn S, et al. Factors influencing the fracture of nickel-titanium rotary instruments. Int Endod J 2003;36:262-66.

29- Pérez-Higueras JJ, Arias A, de la Macorra JC. Cyclic fatigue resistance of $\mathrm{K} 3, \mathrm{~K} 3 \mathrm{XF}$, and twisted file nickel-titanium files under continuous rotation or reciprocating motion. J Endod 2013;39:1585-88.

30- Spencer HR, Ike V, Brennan PA. Review: the use of sodium hypochlorite in endodontics - potential complica- tions and their management. British Dental Journal 2007; 202: 555-9. 
31- Putzer P, Hoy L, Gunay H. Highly concentrated EDTA gel improves cleaning efficiency of root canal preparation in vitro. Clinical Oral Investigations 2008;12: 319-24.

32- O’Hoy PY, Messer HH, Palamara JE. The effect of cleaning procedures on fracture properties and corrosion of $\mathrm{NiTi}$ files. Int Endod J 2003; 36: 724-32.

33- Karataşlıoğlu E, Aydın U, Yıldırım C. Cyclic Fatigue Resistance of Novel Rotary Files Manufactured from Different Thermal Treated Nickel-Titanium Wires in Artificial Canals. Nigerian Journal of Clinical Practice 21 2018;Issue $2: 232-235$.

34- Y1lmaz K and Ozyürek T. Comparison of the cyclic fatigue resistance of nickel-titanium rotary instruments manufactured using controlled memory wire.Turk Endod J 2017;2(1):5-9 .

35- Shen Y, Qian W, Abtin H, Gao Y and Haapasalo M. Effect of Environment on Fatigue Failure of Controlled Memory Wire Nickel-Titanium Rotary Instruments. J Endod 2012; 38:376-380.

36- Shen Y, Zhou HM, Zheng YF, Campbell L, Peng B, Haapasalo M. Metallurgical characterization of controlled memory wire nickel-titanium rotary instruments. J Endod 2011; 37: 1566-71.

37- Pedulla E, Grande NM, Plotino G, Pappalardo A, Rapisarda E. Cyclic fatigue resis- tance of three different nickel-titanium instruments after immersion in sodium hypochlorite. J Endod 2010;37:1139-42.

38- Madhusudhana K, Archanagupta K, Suneelkumar C, Lavanya A, D Mandava. Effect of addition of lycopene to calcium hydroxide and chlorhexidine as intracanal medicament on fracture resistance of radicular dentin at two different time intervals: An in vitro study. Journal of Conservative Dentistry 2015;18: 205-209. 